\title{
Arte e esclarecimento: proposta de aproximação a partir do pensamento de Theodor W. Adorno
}

\author{
JESSICA DICHIARA *
}

\footnotetext{
* Mestranda em Filosofia pela Universidade Federal Fluminense (UFF)

RESUMO O objetivo amplo deste texto é fazer apontamentos sobre a relação entre arte e esclarecimento no pensamento do Adorno. Partindo da crítica da cultura relacionada à forma do pensamento no mundo administrado, a hipótese que guia este trabalho é a de que, ao colocar em questão a forma do romance contemporâneo a partir de uma discussão sobre a posição do narrador, Theodor W. Adorno mostra como a prosa poética pode ensinar algo para o pensamento que tem a ver com a escritura e que faz a filosofia se repensar em sua materialidade. Para tanto, três textos do autor serão mobilizados: "O conceito de esclarecimento” que abre o livro Dialética do Esclarecimento, de 1947, escrito em conjunto com Max Horkheimer; "Posição do narrador no romance contemporâneo" e "O ensaio como forma”, ambos os ensaios encontrados no primeiro volume de suas Notas de Literatura, publicado em 1958.

PALAVRAS-ChAVE Theodor W. Adorno, teoria crítica, esclarecimento, ensaio, arte.

ABSTRACT The broad objective of this text is to make notes on the relation between art and enlightenment in Adorno's thought. From the critique of culture related to the form of thought in the administered world, the hypothesis guiding this work is that, by calling into question the form of the contemporary novel from a discussion of the narrator's position, Theodor W. Adorno shows as poetic prose can teach something to thinking that has to do with writing and that makes philosophy rethink its materiality. To do so, three texts of the author will be mobilized: "The concept of enlightenment" that opens the book Dialectic of Enlightment (1947), written with Max Horkheimer; "The Position of the Narrator in the Contemporary Novel" and "The Essay as Form", both essays found in the first volume of his Notes of Literature I, published in 1958.

KEYWORDS Theodor W. Adorno, critical theory, enlightenment, essay, art. 
"O que transforma a noite em luz? A poesia." Jean-Luc Godard, Alphaville, 1965

PARTindo da crítica da cultura relacionada à forma do pensamento no mundo administrado, a hipótese que guia este trabalho é a de que, ao colocar em questão a forma do romance contemporâneo a partir de uma discussão sobre a posição do narrador, Theodor W. Adorno mostra como a prosa poética pode ensinar algo para o pensamento que tem a ver com a escritura e que faz a filosofia se repensar em sua materialidade. $\mathrm{O}$ objetivo amplo deste texto é fazer apontamentos sobre a relação entre arte e esclarecimento no pensamento do Adorno. Para dar conta disso, num primeiro momento me apoio na leitura do fragmento "O conceito de esclarecimento" que abre o livro Dialética do Esclarecimento (1947), escrito em conjunto com Max Horkheimer, com a intenção de elucidar o diagnóstico do fracasso do projeto do esclarecimento a partir da perda da reflexividade inerente à razão que teria se instrumentalizado. No segundo momento o texto “Posição do narrador no romance contemporâneo” (1958) guia, pela máxima adorniana de que "na transcendência estética reflete-se o desencantamento do mundo" , os apontamentos. O pensamento racional instrumentalizado, ao perder sua capacidade reflexiva, teria deslocado para a arte este potencial de liberação, e esta capacidade guardaria relações com a forma poética. E por fim, a partir da investigação sobre a posição do narrador no romance contemporâneo, o terceiro momento deste trabalho se volta novamente sobre a escrita filosófica ao relacionar esse texto com "O ensaio como forma" (1958), ambos os ensaios encontrados no livro Notas de Literatura I.

\section{“O CONCEITO DE ESCLARECIMENTO” E O DIAGNÓSTICO DO PRESENTE}

Em “O conceito de esclarecimento", Adorno e Horkheimer tentam entender, segundo Jeanne Marie Gagnebin, “como o antigo ideal de razão emancipadora, ideal explícito no Iluminismo, mas (...) já presente na origem da racionalidade ocidental, (...)

1 ADORNO, T. W. Posição do narrador no romance contemporâneo, p. 58. 
deu à luz um sistema social no qual racionalidade e dominação são inseparáveis". ${ }^{2}$ Escrevendo já a partir do fracasso desse projeto de esclarecimento, para eles seria necessário entender o que aí estava em jogo justamente porque o "progresso do pensamento", entendido num sentido amplo, teria sua origem num sentimento básico: o medo que o homem sentia frente às forças da natureza (entendidas como mágicas) e à violência social. Sendo o pensar desencadeado pelo medo, o saber brotaria dessa tensão entre o medo vivido e a vontade de emancipação.

Trata-se, em “O conceito de esclarecimento”, de um modo geral, da tarefa crítica de investigar o modelo de racionalidade que funda o mundo ocidental e que continua a atuar no pensamento contemporâneo. A ideia central deste fragmento pode ser apresentada como um alerta que pretende revelar o quão pouco racional o mundo realmente se tornara a partir do processo de desmistificação supostamente libertário em jogo no esclarecimento, cujo mote principal era o desencantamento do mundo. Cito aqui as famosas frases que iniciam o texto: "No sentido mais amplo do progresso do pensamento, o esclarecimento tem perseguido sempre o objetivo de livrar os homens do medo e de investi-los na posição de senhores. Mas a terra totalmente esclarecida resplandece sob o signo de uma calamidade triunfal". ${ }^{3}$

Elaborando como a razão não consegue dar conta da promessa de liberdade (e felicidade) do esclarecimento - que seria a de emancipar o homem do medo através da dominação pelo desenvolvimento da técnica -, mas, muito pelo contrário, por ser instrumentalizada, passa a servir à promoção, à manutenção e à intensificação das desigualdades entre os próprios homens, é assim que a crítica ao pensamento (razão instrumental) desdobra-se em crítica à cultura (mundo administrado) no desenvolvimento do texto adorniano. A catástrofe representada pelo holocausto (se é que podemos nos referir a essa questão a partir de um referencial representativo), mas não só por ele, é vinculada, assim, ao uso de mais razão (instrumental) e técnica, e não ao irracionalismo.

Com base nesse diagnóstico desconcertante de que a "recaída" do esclarecimento na barbárie (ou na mitologia) não deve ser lida como regressão e sim como produção 
de um pensamento esclarecido, só que "paralisado pelo temor da verdade" 4 , a teoria crítica de Adorno será comprometida justamente com um projeto que ele próprio intitulará posteriormente como sendo uma Dialética Negativa, ou seja, como a negação do projeto de um falso-esclarecimento a partir da radicalização da crítica da razão. Verdade, nesse sentido, é aqui entendida como o negativo, o caráter negativo, a outra face que compõe algo; como a crítica necessária a todas as coisas, inclusive àquelas que afirmamos positivamente como, por exemplo, a razão. A ambiguidade inerente à razão, para além do bem e do mal, torna imperativo assumir que não há pureza, que ela não é constituída apenas por elementos progressivos, mas sim constituída como jogo de forças. Abandonar a reflexão sobre o elemento destrutivo da razão significa perder o seu caráter superador e, por isso, a sua relação com a verdade.

Pensando que outros mundos seriam possíveis a despeito desse aparente enredamento tão total da razão instrumental (aquela razão que não faz a autocrítica), Adorno viu na arte um campo para a reflexão acontecer.

Uma hipótese é a de que, para o filósofo alemão, a arte se apresentaria como um reflexo mediado do mundo real, sendo, assim, elemento crítico e de resistência por excelência no interior da sociedade reificada. Sua função social seria, justamente, liberar-se da barbárie do mundo administrado e, desse modo, constituir-se como negatividade (articulando-se desse modo à verdade), redescobrindo nos objetos as possibilidades que lhes foram negadas na sociedade técnica. Em outras palavras: num mundo onde tudo o que é precisa ser na medida em que é útil a uma função específica - atrelada, via de regra, ao modo de produção de vida capitalista -, a arte nega a utilidade mesma inerente a esse modo de produção. ${ }^{5} \mathrm{E}$ mais: no modo mesmo de sua negatividade, que restauraria o sentido da liberdade para além daquela primeira liberdade sentida pelo homem ao dominar a natureza, a arte parece realizar o projeto do esclarecimento no modo de uma não-dominação.

4 Idem, p. 13.

5 Sob esta perspectiva, arte e filosofia teriam um ponto em comum, que é ressaltado por Adorno como sendo o lócus do ensaio: ocupar um lugar entre os despropósitos. Cf. ADORNO, T. W. O ensaio como forma, p. 17. 


\section{A POSIÇÃO DO NARRADOR NO ROMANCE CONTEMPORÂNEO}

Partindo de um gênero artístico específico, a literatura, e, mais especificamente, do romance do século XX - século este que Hobsbawm caracterizou como a era das catástrofes - Adorno discute o problema do narrador no romance contemporâneo, qual seja: o fato de ser ele aquele que carrega consigo o fardo de ter de continuar a narrar um mundo indizível. Assumindo a tarefa de resumir a situação atual do romance enquanto forma, Adorno destacará a posição do narrador como emblemática para o estatuto do romance por se constituir de um paradoxo: a impossibilidade de narrar, embora a forma do romance exija narração. Desenvolvendo esta tese em conjunção com a tese do realismo inerente ao gênero literário em questão, Adorno propõe uma reflexão sobre as formas pelas quais o romance contemporâneo poderia reagir ao "mundo administrado" devido ao questionamento de seu procedimento intrínseco de sugestão do real. Por ser a forma literária específica da era burguesa, segundo o filósofo alemão, já em seu início, com Dom Quixote, encontramos a experiência do mundo desencantado através da capacidade de dominar artisticamente a mera existência. Assim, o paradoxo do romance contemporâneo (visto sob a ótica da posição do narrador) se dá porque o romance necessita construir a sua identidade mostrando o mundo fragmentado tal qual se apresenta, sem iludir o leitor. A pergunta que se põe é: diante do mundo administrado e do horror da guerra e da experiência do totalitarismo, como é possível continuar narrando? Para Adorno, a narração pressuporia algo de interessante a ser dito, e justamente isso nos falta diante da mesmice, da estandardização e do esvaziamento de sentido a que fomos submetidos pela história. Contendo na sua forma mesma esse engodo, o romance estaria qualificado como poucas outras formas de arte para expor a reificação de todas as relações individuais e sociais que alimentam a alienação e autoalienação do homem. Sendo exigência e necessidade histórica chamá-las pelo nome, Adorno dirá que desde o século XVIII o romance teve "como verdadeiro objeto o conflito entre os homens vivos e as relações petrificadas” ${ }^{\text {e }}$, então, o filósofo-ensaísta definirá o romance moderno como:

O momento anti-realista do romance (...), sua dimensão metafísica, madura em si mesmo pelo seu objeto real: uma sociedade em que os homens estão apartados uns dos outros e de si mesmos. ${ }^{7}$

\footnotetext{
6 Idem, Posição do narrador no romance contemporâneo, p. 58.

7 Idibem.
} 
E é a partir da ideia mesma de que "na transcendência estética reflete-se o desencantamento do mundo" ${ }^{\prime}$, ou seja, de que no absoluto da arte o desencantamento do mundo ao mesmo tempo reflete a si mesmo (como o reflexo do espelho que ao refletir as coisas como imagem torna obrigatório o olhar-se) que esse ensaio apresenta, assim, o que parece ser o problema contemporâneo da arte - que é ao mesmo tempo o que a (e nos) salvaria: encarnar sem compromisso o horror e encontrar prazer na dissonância e no abandono, transformando, ao expor tão brutalmente os elementos mais nocivos da sociedade, aquilo que nos aprisiona naquilo que serviria à nossa emancipação.

Adorno e o grupo de intelectuais reunidos sob o nome posterior de "Escola de Frankfurt” endossavam a necessidade de uma teoria crítica em contraposição à corrente teoria tradicional apoiada em uma racionalidade estreita e demasiadamente confiante em sua onipotência. Isso se apresenta, no âmbito filosófico, a partir da impossibilidade de se seguir pensando a filosofia enquanto sistema, com a constatação da crise tanto do modelo de representação, quanto da falência dos grandes sistemas filosóficos. Ademais, tomam como desafio epistemológico a tentativa de desmistificação da ideia de racionalidade, apontando para a autorrefelxão necessária à razão que fora eclipsada na modernidade segundo o diagnóstico deles. A denúncia do positivismo, a crítica imanente, o princípio da não-identidade, a autorreflexividade e a antipatia estética e política pela sociedade burguesa são as grandes características do pensamento adorniano, e é a partir desse conjunto de pressupostos que Adorno repensará a escrita filosófica como uma forma de pensamento que guarda relações estreitas com a escritura poética.

\section{O ENSAIO COMO FORMA E O FUTURO DA ESCRITA FILOSÓFICA}

Nos processos do pensamento, a dúvida quanto ao direito incondicional do método foi levantada quase tão-somente pelo ensaio. Este leva em conta a consciência da não-identidade, mesmo sem expressá-la; é radical no não-radicalismo, ao se abster de qualquer redução a um princípio e ao acentuar, em seu caráter fragmentário, o parcial diante do total. ${ }^{9}$

Não admitindo que nada lhe seja prescrito, para Adorno o ensaio não é nem ciência nem arte; não pretende “alcançar cientificamente” nem “criar artisticamente alguma

8 Ibidem.

9 Idem. O ensaio como forma, p. 25. 
coisa." ${ }^{10}$ Forma contemporânea de apresentação do pensamento, o ensaio evoca a liberdade de espírito que até hoje não conseguiu se desenvolver, a partir da imagem da disponibilidade de uma criança que se entusiasma com os objetos que existem no mundo. Partindo do que deseja falar, e não de um princípio primeiro, o ensaio se mostra capaz de possibilitar novas formas de expressão e pensamento, justamente pelo fato de estar atrelado à especulação sobre objetos específicos. Adorno tematiza, assim, a escrita filosófica como aquela a habitar "um lugar entre os despropósitos" ${ }^{11}$.

Em relação ao procedimento científico e sua fundamentação filosófica enquanto método, o ensaio se posiciona a partir da crítica da ideia de sistema. Como consequência dessa crítica, ele "recua, assustado, diante da violência do dogma, que atribui dignidade ontológica ao resultado da abstração, ao conceito invariável no tempo, por oposição ao individual nele subsumido." ${ }^{12}$ Isso significa dizer que o paradigma de um pensamento que contrapõe verdade e história como opostos irreconciliáveis e/ou uma filosofia onde o critério é metafísico-ontológico e atemporal, devem ser sobrepujados. Quando a noção de verdade começa a incluir a história em seu pensamento "o a posteriori tornar-se concretamente um a priori" ${ }^{13}$, ou seja, o historicamente produzido passa a ser considerado objeto da teoria e, assim, a distinção entre uma "Filosofia Primeira" e uma "mera filosofia da cultura" ${ }^{14}$ não é sustentável no ensaio. Podemos pensar que a forma ensaística desenvolve-se concomitantemente à filosofia da cultura porque o critério filosófico anterior era metafísico-ontológico e atemporal e pressupunha o sistema.

Desafiando os ideais de clareza e distinção e da certeza livre de dúvidas, o procedimento do ensaio esboça um pensamento anti-sistema, mas sistemático. A sistematicidade do ensaio estaria em operar metodologicamente sem método, ressaltando o caráter momentâneo do acontecimento da verdade. Cabe dizer que a verdade, aqui, configura-se como um esforço de reorganização conceitual (quer dizer, material) dos elementos de que as coisas no mundo são formadas. Sendo um momento de auto-

\footnotetext{
10 Idem, p. 16.

11 Idem, p. 17.

12 Idem, p. 25.

13 Idem, p. 26.

14 Ibidem.
} 
-exposição, ela é um fragmento aberto que, na realização da experiência do encontro do filósofo-crítico com o objeto, ilumina-se e aparece como cristalização das forças históricas tanto do momento de sua origem como da época presente, tudo isso na materialidade do texto. A forma do ensaio é justamente essa experiência intelectual de cuja memória o processo de engendramento do conceito não deve ser apagado. $\mathrm{O}$ problema do método científico é justamente esse esquecimento.

Não pressupondo também nem a totalidade como algo dado, nem a identidade entre sujeito e objeto, o que o ensaio almeja, o teor de sua verdade, tem a ver com "eternizar o transitório", o que advém do gesto material de se escrever ensaios. Suspendendo o conceito tradicional de método, na esteira da formulação benjaminiana de que “método é caminho indireto, é desvio" ${ }^{15}$, o pensamento vai formando constelações a partir dos conceitos introduzidos no texto para falar de um objeto específico, relação essa tão mais rica quanto menos redutora. Os conceitos, que são sim o meio específico do ensaio para Adorno ${ }^{16}$, não servem para reduzir os fenômenos, mas sim para “unificar livremente pelo pensamento o que se encontra unido nos objetos de sua livre escolha" ${ }^{17}$ [da escolha do ensaísta]. É nesse esforço de apresentação que o ensaio se aproxima da obra de arte em geral e da literatura, especificamente. E a posição do narrador no romance contemporâneo aparece análoga à do filósofo-ensaísta, pois o ensaio deseja a experiência intelectual como modelo; toma como tarefa reconstituir essa experiência a partir da reconfiguração do objeto. Assim, tenta fixar o movimento das forças contidas no objeto determinado a partir dos conceitos mobilizados no texto. Este movimento de retorno tanto ao objeto quanto aos conceitos é propriamente o movimento da filosofia e é neste ponto que o ensaio faz convergirem arte e filosofia. Assim a possível relação entre arte e esclarecimento na filosofia de Theodor W. Adorno é que a arte, em sua recusa a subordinar a natureza ao pensamento e a matéria ao espírito, forneceria um modelo utópico daquilo que a humanidade, apesar de tudo,

15 BENJAMIN, W. Prólogo epistemológico-crítico, p. 16.

16 Esse é o ponto de discórdia entre Adorno e Lukács: “o ensaio se aproxima de uma autonomia estética que pode ser facilmente acusada de ter sido apenas tomada de empréstimo à arte, embora o ensaio se diferencie da arte tanto por seu meio específico, os conceitos, quanto por sua pretensão à verdade desprovida de aparência estética. É isso o que Lukács não percebeu quando (...) definiu o ensaio como uma forma artística." ADORNO, T. W. O ensaio como forma, p. 18.

17 Idem, p. 27. 
pode tornar-se. Esta questão, central no tempo de Adorno, elaborada há pelo menos cinco décadas, ainda não se extinguiu, e a hipótese deste trabalho é de que a arte como pensada por Adorno apresenta esse potencial crítico no seio da sociedade, e sua discussão depende de que se vá além da dicotomia tradicional entre "arte pela arte" e “arte engajada”. Pensar a arte como lugar de crítica, liberação e per-feição do esclarecimento significa encontrar nela a possibilidade de um novo mundo no nosso mundo, habitado por homens verdadeiramente humanos. E esta arte, reflexiva e humanizada, teria muito a ensinar ao pensamento filosófico eclipsado pela instrumentalização da razão e da forma. Se para Adorno a filosofia cresce ali onde não há imposição, mas sim necessidade, então a tentativa de organização filosófica parece muito mais sempre abarcar as partes constitutivas dos fenômenos do que reduzi-los a uma verificação e, assim, no que diz respeito a esse procedimento metodológico, a arte parece ter muito que dizer, por ser inerente a ela apresentar ao mundo novas organizações, ao mesmo tempo livres e necessárias. É neste ponto específico que a relação entre arte e esclarecimento se apresentam, a partir do pensamento de Adorno, como inteiramente interligados. No caso específico do ensaio, ele é o modo de apresentação de um pensamento que faz convergirem teoria estética e teoria do conhecimento.

\section{BIBLIOGRAFIA}

ADORNO, T. W. \& HORKHEIMER, M. “O conceito de esclarecimento” In: Dialética do esclarecimento: fragmentos filosóficos. Trad. Guido de Almeida. Rio de Janeiro: Ed. Zahar, 1985. ADORNO, T. W. Notas de Literatura I. Trad. Jorge de Almeida. São Paulo: Ed. 34, 2003. BENJAMIN, W. "Prólogo epistemológico-crítico” In: Origem do drama trágico alemão; edição e tradução: João Barrento. Belo Horizonte: Ed. Autêntica, 2011.

GAGNEBIN, J. M. “Do conceito de razão em Adorno” In: Sete aulas sobre linguagem, memória e história. Rio de Janeiro: Ed. Imago, 2005. 